\title{
CORRESPONDENCE
}

\section{New IQ test?}

$\mathrm{SiR}_{\mathrm{R}}$ - Mackintosh ${ }^{1}$ finds my theory of intelligence "distinctly simple" but allows that the findings of the inspection-time (IT) studies are "possibly very important". I largely agree with him on both counts. No one who has steeped himself in modern "cognitive psychology" - with its legions of black boxes, "executive programmes" and "subroutines", resembling phrenology in all but the apparent infinity of the number of mental mechanisms that are now conjectured - can readily accept that intelligence is truly general or unitary. As Mackintosh writes, "there might be a variety of independent traits, which happened to correlate with one another in the general population." Such a lofty invocation of chance "happenings" is commonly preferred by cognitivists to any systematic endeavour to explain why so many measures of mental ability correlate positively as they do.

Professor Mackintosh writes: "A correlation between IQ and inspection time does not mean that IQ is mental speed, nor even that speed is one (of several) causes of IQ." I quite agree with him on the first point - if only for the reason that it is important to distinguish between the hypothesized "mental speed" on the one hand and its natural, developmental products (in conventional IQ) on the other. But Mackintosh offers no support for his suggestion that the causal relationship between speed and IQ "might even go in the reverse direction". It is easy, and indeed very traditional to suggest that a higher IQ gives a person many advantages. But why should one of the largest of these advantages - larger than those for educational attainment, income or social prestige - be in judging briefly presented linelengths? Again, if IQ were causal to IT, it should be noted that one of the studies which I have reported (by Brenda Hosie) found a strong correlation $(-0.78)$ between IQ and IT in children who were only four years old. This hardly looks like a straightforward case of a high IQ providing numerous, small and cumulative advantages over a long period of development.

I do not claim to have "proved" that mental speed is psychologically and ontogenetically basic to IQ-differences. Indeed, even when it becomes possible to manipulate inspection times experimentally (by drugs, for example), mental speed differences may not be able to account for at least that 20 per cent of natural IQ variance that is widely agreed to be "environmental" in origin. However, I do suppose that scholars of cognitivist and environmentalist persuasions will need great imaginativeness to formulate explanations of the IQ-IT relationship that do not involve the concept of a unitary, underlying trait for which $g$ is the timehonoured name and psychometric indicator, and for which "mental speed" will prove a convenient psychological short-hand.

There are numerous potential applications of the finding that IT (and, as Jensen and the Hendricksons find, "choice reaction time" and the "average evoked cortical potential") can apparently serve to index intelligence. It should at last be possible to operationalize the concept of intelligence in studies of young human infants and of other species; and this may lead to rapid advances and changes in the understanding of how intelligence is controlled and of how it develops. But Mackintosh doubts that any results obtained with different human racial groups could influence cherished convictions. I fail to understand why. My own view - outlined in a forthcoming paper happens to be that conventional measures of fluid intelligence are not quite such pure measures of $g$ as Jensen loyally maintains: this is principally because some of them are a little contaminated by $k: m$ (or "spatial abilities"). I, for one, would feel obliged to modify this view if IT indices gave Afro-Americans the same degree of disadvantage that they have on conventional measures of IQ. Whether "the critics of IQ" could ever be persuaded to change their views as a result of such studies is not the question. So long as the IQ-IT relationship proves generally replicable, new evidence about IT in non-WASP subjects should have appropriate effects on the scientific views of all reasonable people.

C.R. BRAND

Department of Psychology,

University of Edinburgh, Edinburgh, UK

1. Mackintosh, N.J. Nature 289, 529-530 (1981).

2. Brand, C.R. \& Deary, in Models of Intelligence (ed. Eysenck, H.J.) (in preparation).

\section{Darwin's survival}

SIR - Your leading article "Darwin's death in South Kensington" (Nature 26 February, p.735) illustrates "the rot at the museum" by quoting a passage from our 1978 Guide. How odd, for that passage was drafted (by me) as a conscious paraphrase of the part of Chapter 13 in The Origin of Species in which Darwin discussed the relation between his theory and systematics. "Groups-within-groups classification", which you take to be a "popular euphemism for cladism" and its attendant heresies, is not hidden propaganda but a contraction of Darwin's words - "the grand fact in natural history of the subordination of group under group."

The "weasel words" which so incense you are "If the theory of evolution is true." I have tried replacing them by your own criterion of truth: "If the theory of evolution is not an open question among serious biologists, the features used to classify species in groups . were acquired by the common ancestor of the group." It does not read well.

Your readers may try the substitution in the equivalent passage from Darwin: "on the view that the natural system is founded on descent with modification... the characters which naturalists consider as showing true affinity between any two or more species, are those which have been inherited from a common parent." And your readers can answer for themselves your question "what purpose except general confusion can be served by these weasel words?" The reader may also be able to judge whether the rot is to be found here or in Little Essex Street.

Colin Patterson

British Museum (Natural History),

London $S W 7, U K$
SIR - As working biologists at the British Museum (Natural History) we were astonished to read your editorial "Darwin's death in South Kensington' (Nature 26 February, p.735). How is it that a journal such as yours that is devoted to science and its practice can advocate that theory be presented as fact? This is the stuff of prejudice, not science, and as scientists our basic concern is to keep an open mind on the unknowable. Surely it should not be otherwise?

You suggest that most of us would rather lose our right hands than begin a sentence with the phrase "If the theory of evolution is true

"Are we to take it that evolution is a fact, proven to the limits of scientific rigour? If that is the inference then we must disagree most strongly. We have no absolute proof of the theory of evolution. What we do have is overwhelming circumstantial evidence in favour of it and as yet no better alternative. But the theory of evolution would be abandoned tomorrow if a better theory appeared.

Charles Darwin died nearly a century ago and is honoured at South Kensington as a great man of science. It does neither him nor science any service to misrepresent the status of his work.

H. W. Ball, A. Gray, L.A. Mound,

J.F.M. CANNON, C.J. Humphries, H.M. Platt, G.C.S. Clarke, P.W. James, J.H. Price, R.F. Eastwood, A.C. Jermy, N.K. B. ROBSON, P.L. ForeY, D.M. JOHN, C.B. Stringer, J.D. George, S.W. Jones, D.A. Sutton, M.Gibby, R.S. Miles,

R.I. VANE-WRIGHT AND P.J.P. WhITEHEAD Departments of Botany, Entomology, Palaeontology, Public Services and Zoology, British Museum (Natural History), London $S W 7, U K$

\section{Conservation sites}

SIR - It can hardly be doubted that the number of species alive today is much smaller than the number of extinct species, nor that the future, unless it be preternaturally terminated, will see a proliferation of types of life exceeding all which have gone before. From this I conclude that extinction is the normal if not the necessary consummation of any species. If this is so, to attribute value to any species simply because it happens to coexist with an observer, and still more, to attribute greater value to a species which, by its rarity, demonstrates its biological deficiency, reveals in that observer either or both a level of prejudice and lack of reason which gives cause to doubt his judgement on the matter of conservation even though he be a professional. Yet this is the essence of the action of the Nature Conservation Council in designating "sites of special scientific interest". Were these sites to be set up with no loss of freedom to anyone, and more importantly, no cost to any individual, their institution might be treated as innocent caprice. The real consequence of the foolish advice given by the Nature Conservation Council is that their political masters impoverish the owners of the land involved, in the belief that they are preserving a national or even international treasure. Dr Goode of the

Continued on page 173 


\section{Continued from page 82}

Nature Conservation Council has publicly stated that such sites are "gems" (BBC Radio 4,22 January). He is indeed correct, for, like jewels, they provide neither nourishment nor habitation nor protection (the three necessities of life). But they are worse than jewels for they cannot be traded in time of hardship and instead of representing riches they are a permanent impoverishment to their owners. The usual epithet for such items is "white elephants".

Let us have no more of this folly in the name of science. The value to science of any objects or phenomena lies not in themselves but in the information they yield to study. Once this information is recorded and published whatever value remains in the objects or phenomena is of no value to science, for unless the original study was incompetently executed nothing new will be learned by preservation. I do not in the least condone the wilful pursuit of rare organisms, or the careless or selfish pollution of the environment, and I admit the possible future benefits which may be derived by maintaining "gene banks" of rare forms of cultivated organisms, but all that is quite a different matter. Should there be a popular demand for the preservation of areas of wilderness then justice requires that the populace provide compensation to the owners, but let there be no mistaken idea that this cost, which will be measured in hundreds of thousands of pounds annually, is a deserving use of the funds made available to science, nor that compulsion is justified by the supposed advance of knowledge. If any individual or body of scientists presumes that it is only necessary to legislate or to spend enough money in order to halt not only natural selection but also the very evolution of the inaminate world, such presumption is an affront to reason and must bear the condemnation of responsible scientists for misleading those who know no better.

\section{MuIR}

Department of Zoology,

The University, St Andrews, UK

\section{Origin of cancer}

SIR - Cairns's ${ }^{1}$ article is a welcome breath of fresh air in trying to put the causes of cancer into a realistic perspective. However, he could have strengthened his case for genetic transposition as a major cause by considering the relevance of DNA double-strand breaks as a molecular mechanism. Over the last few years Leenhouts and Chadwick ${ }^{2}$ have convincingly demonstrated that the biochemical basis of malignancy lies most probably in the generation of double-strand breaks-lesions which cannot be repaired but which may result in genetic transposition. The evidence comes from many sources including those quoted by Cairns as well as radiation damage effects and cell-fusion experiments. Since double-strand breaks are necessary for some mutations, chromosomal abnormalities and genetic transpositions, Occam's razor would suggest this as a suitable model on which to test Cairns's hypothesis.

D.I. EDWARDS

Department of Paramedical Science,

North East London Polytechnic,

London E15, UK

1. Cairns, J. Nature 289, 353.357 (1981).

2. Leenhouts, M.P. \& Chadwick, K.M. Int. J. Radiat. Biol. 33, 357-370 (1978).

SIR - John Cairns's speculative article ${ }^{1}$ on the origin of human cancer is open to criticism both for what it says and for what it leaves unsaid.

Garner and Hertzog ${ }^{2}$ have already drawn attention to the tenuous nature of the evidence on which Cairns bases his suggestion that "Chemical mutagens (of the kind detected in the usual tests for mutagenicity) seem unlikely to be rate-limiting components in most human carcinogenesis" and that "large-scale changes in the genome (such as rearrangements and deletions) seem to be more hazardous than the local changes produced by conventional mutagens". They might have put their case even more strongly.

First, the fact that patients with xeroderma pigmentosum (XP) do not show a high incidence of cancer in tissues other than skin may imply only that cancer in these other tissues is not associated with the formation of "UV-like" lesions ${ }^{3}$ because the essential anomaly in XP seems to be failure to recognize lesions of this kind rather than inability to excise and repair DNA lesions in general.

Second, the association of chromosomal abnormalities with a high incidence of leukaemias, lymphomas and carcinomas in patients with Bloom's syndrome tells us nothing about the aetiology of cancer in the vast majority of the population who do not have Bloom's syndrome. Similarly it seems unjustifiable to assume that most cancer cells have an abnormal karyotype simply because this is often the case with cells from leukaemias, lymphomas, meningiomas and gliomas. Moreover, even if this generalization were true, it is conceivable, as Cairns himself points out, that the observed chromosomal rearrangements could have resulted from "trivial secondary events that occur after all the rate-limiting steps of carcinogenesis have been completed".

Third, it is not clear how the phenomenon of carcinogenesis in experimental animals by implanted films of plastic (and other materials) supports Cairns's argument. The underlying mechanism is still far from clear but, contrary to what Cairns suggests, Karp et $a l^{4}$ (whose work he cites) concluded that the hypothesis that tumours develop because the cells have lost the restraining influence provided by contact with each other, was specifically excluded by their observations. It is also worth pointing out that this form of carcinogenesis does not seem to have been reported in man despite the fact that foreign material of various kinds, and sometimes in sheet form, has been used in human surgery for many years (for example, in hernia repair, orthopaedic surgery and vascular surgery).

Finally, even if large-scale changes in the genome were shown to occur in cells from most common human cancers, this would not exclude the possibility that environmental pollution by chemical mutagens of various kinds, including mutagens detectable by the Ames test, plays an important part in the aetiology of human cancer. Many such mutagens, as Garner and Hertzog point out, and as Cairns admits, can increase the frequency of sister chromatid exchange and cause other chromosomal interactions in mammalian cells. The extent to which such changes are "functionally equivalent to genetic transpositions" seems to be of secondary importance in comparison with the question of whether or not they are associated with a high incidence of cancer.

As regards what is left unsaid, Cairns seems to equate "the creation of a cancer cell" with the development of cancer. Thus, while he recognizes the possible role of DNA repair mechanisms in preventing the emergence of cancer cells, he ignores the possibility, which I have discussed at length elsewhere $e^{5}$, that homeostatic mechanisms of another kind may operate to destroy transformed cells or prevent them from dividing, and thus prevent the development of overt cancer. It is clear from the work of Mondale and Heidelberger ${ }^{6}$, and others, which Cairns cites, that there may be a long interval between the application of a mutagen to cells in tissue culture and the emergence on repeated subculture of cells with the hallmarks of malignant transformation. The mechanisms responsible have not been fully elucidated but there seems no reason to doubt that they also operate in vivo and play a part in delaying the development of tumours in response to exposure to chemical and physical carcinogens; this, however, does not exclude the possibility that, in vivo, other mechanisms are also involved.

The long interval, often of many years' duration, which can occur between the locally successful removal of a primary tumour and the appearance of metastases would seem to imply either that cancer cells can remain dormant, or that cell proliferation may be balanced by cell death, for a long time, and studies of tumour cell population kinetics in both animals and man confirm this conclusion ${ }^{5}$. It has, moreover, been observed that the period of apparent dormancy may be abruptly terminated by experimental ${ }^{7}$ or therapeutic ${ }^{8}$ procedures. If metastatic tumours can be held in check in this way, why not primary tumours? My colleagues and I have recently described a technique which makes it possible to investigate this question directly in an animal model ${ }^{9,10}$.

Michael WoOdrufF

MRC Clinical and Population

Cytogenetics Unit,

Western General Hospital,

Edinburgh, UK

1. Cairns, J. Nature 289, 353-357 (1981)

2. Garner, R.C. \& Hertzog, P.J. Nature 289, 627 (1981).

3. Regan, J.D. \& Setlow, R.B. Cancer Res 34, 3318-3325 (1974).

Karp, R.D. et al. J. natn. Cancer Inst. 51, 1275-1285 (1973).

5. Woodruff, M.F.A. The Interaction of Cancer and Host (Grune \& Stratton, New York, 1980).

6. Mondale, S. \& Heidelberger, C. Proc. natn. Acad. Sci. U.S.A. 65, 219-225 (1970)

7. Eccles, S.A. \& Alexander, P. Nature 257, $52-53$ (1975).

8. Woodruff. M. A A Nature 258, 776 (1975)

9. Woodruff M.F A et al Proc $R$ SOC. $B$ (in the press).

10. I thank Professor H.J. Evans for his helpful comments on this letter.
the 